\title{
Digital Innovations for Aged Care: Impacts in the COVID-19 Pandemic
}

\author{
Alan TAYLOR, Jennifer TIEMAN and Anthony MAEDER ${ }^{1}$ \\ Flinders University, Adelaide, Australia
}

\begin{abstract}
This paper describes the extent to which remote interaction healthcare interventions supported by digital technology are currently being used, or have recently been newly developed for use, in the care of older people in Australia within the context of the existing Australian aged care system and in conjunction with the COVID-19 pandemic. We place emphasis on those interventions associated with primary care provision, and associated healthcare services such as allied health, rather than outreach from jurisdictional health services and acute care. The primary purpose of this study was to gain an indication of the extent and range of such interventions, and provide a pragmatic commentary on their usage. This has enabled the understanding of some characteristics for success, and drivers for rapid adoption of further digital technology interventions, in the aged care sector.
\end{abstract}

Keywords. aged care, digital technology, COVID-19 pandemic

\section{Introduction}

Historically, the role for digital technology in the aged care sector has tended to focus on improving access to healthcare. For instance, the National Health and Hospitals Reform Commission recommended to provide "improved access to e-health, online and telephonic health advice by older people and their carers and home and personal security technology" [1], p. 94. Digital technology has been increasingly promoted as central to the healthcare of older people. The Australian Medical Association argued that "aged care sector needs be supported to adopt modern eHealth systems which enable more effective and efficient patient management" [2], p. 2.

However, despite these arguments the roles in supporting aged care and the extent and impact of digital technology-based interventions remain unclear. This study seeks to establish the extent to which a specific class of remote interaction healthcare interventions supported by digital technology are currently being used, or have recently been newly developed for use, in the care of older people in Australia within the context of the existing Australian aged care system and the COVID-19 pandemic. We place emphasis on those interventions associated with primary care provision, and associated healthcare services such as allied health, rather than outreach from jurisdictional health services and acute care, which are not specifically targeted at supporting the aged care sector.

The primary purpose of this study was to gain an indication of the extent and range of such interventions, and to provide a pragmatic commentary on their scope and usage.

${ }^{1}$ Corresponding Author, Anthony Maeder, Flinders Digital Health Research Centre, Flinders University, 1284 South Road, Tonsley SA 5042, Australia; E-mail: Anthony.maeder@flinders.edu.au. 
It was anticipated that this exercise would enable the understanding of some characteristics for success, and drivers for rapid adoption of further digital technology interventions, in the aged care sector.

We first provide an overview of aspects of the aged care environment which influence digital technology solutions and the associated changes in service delivery and care models. Next, we present the method and results for the main part of the study, with findings categorised into 4 themes for digital technology supported interventions, and provide a commentary with some examples for these. Then we discuss measures reported at government and corporate levels which have been undertaken or could be undertaken, to enable rapid and widespread adoption of these types of digital technology interventions. Finally we conclude with a summary of our findings according to the derived categorization framework.

\section{Aged Care and Digital Technology}

The Commonwealth Government Aged Care Act (2013) sets out a number of objectives for aged care including promotion of the wellbeing and independence of older people (and their carers), equitable access to age care, provision of high-quality care to meet individuals' needs, protection of the health and wellbeing of care recipients, and improvement in the integration of aged care services with healthcare services. The aged care system is large, complex and highly decentralised. According to the Australian Institute of Health and Welfare [3] there were 1.2 million people in 2017-18 participating in the aged care system at a total cost to governments of $\$ 18.4$ billion. The complexity and decentralised nature of the system arises from the number of service providers and the number of different programs administered: over 5,000 businesses were providing services under seven broad-based programs in 2018-19 [4].

In broad terms the digital technologies used by aged care services fall into two major groups [5]: communications technologies such as the telephone, video conferencing, and many forms of messaging, and technologies used to gather and transmit health information relevant to the maintenance of the health of older people such as remote monitoring. Other distinct groups are technology assisted or supported care using standalone elements such as devices or robotics, and intelligent health information systems such as health portals or online care resources [5]. The paucity of support at national level for widespread innovation and deployment of digital technologies such as these "reflects the wider issue of technology being regarded as an afterthought to service provision, rather than being embedded as a critical enabler of services and their underpinning systems" [6], p. 21.

\section{Methodology}

This study concentrated on digital technology interventions concerned with remote delivery of health services involving active or passive interaction between a health professional and an aged care consumer, by using some form of telecommunications mechanism and associated control and data management tools. The method used was a rapid review based on public media and literature, primarily grey literature (magazine articles, websites), and a few recently published academic articles. This method was chosen mainly due to the absence of comprehensive academic literature on this topic, as 
the pandemic has been a very recent event compared with the timescale of research studies and peer review publication appearance. For description and pragmatic commentary on interventions, the chosen target sources were seen as the best option for locating current information on relevant applications of digital technology in aged care.

The search period for the study was 1 Dec 2019 to 15 June 2020, the limited period necessitating use of rapid review methodology. The search strategy consisted of three arms. First a Google search for items that referred to (Aged care AND (Telehealth OR Telecare OR Telemedicine)) was performed, and the Google search returns were scanned for relevant Australian examples. Second, scanning searches were performed over the timeline of interest on ICT and aged care industry online publications and websites (e.g. Australian Ageing Agenda, Community Care Review, HelloCare, Pulse+IT), with chaining of links of interest from those sources. Third, reference snowballing was undertaken on recent relevant government related sources such as submission documents and reports (e.g. Royal Commission into Aged Care Quality and Safety).

Decisions on inclusions were made by one expert reviewer (the first author) and the resulting summary of those was checked by the other two authors. A major limitation of this search strategy was that programs and services which had not publicised themselves or did not describe their program as telehealth, telecare or telemedicine service, were not captured. Given the large volume of exposure that has been given to the use of health technology during the pandemic, and the breadth of discourse around telehealth as a generic enabling technology, this was deemed an acceptable limitation. We did not analyse social media feeds (e.g. Twitter, Linkedin) because a large amount of clutter would need to be eliminated, and because most information of value from those sources is repeated in edited media and would be captured in the second arm. The study results should thus be seen as representative rather than comprehensive, and may have excluded some other types of niche digital technology-based services which have been made available to support older people.

\section{Results}

Our approach yielded 40 instances of interventions which were accepted by consensus as being within scope. Over half of the interventions were reported as being delivered nationally or in multiple States (23 instances). Of those occurring only in individual States, the majority were associated with higher density east coast States: Qld (5), Vic (5), NSW (4), and SA (3). These interventions were delivered by a total of 35 different providers or businesses: 16 of these were health services providers, 12 were aged care and community care organisations, and 7 were suppliers of technology-based products and services.

Thematic analysis of the search results found four major categories of digital technology supported interventions which were reported as being used in the aged care sector:

- remote consultations for healthcare services;

- remote monitoring of the health state of people;

- $\quad$ support for the independent living of older people;

- communications between older people and their carers.

Four distinct delivery settings were identified: 
- $\quad$ self care, people managing their own health care services needs;

- $\quad$ home care, service provider managed health care in people's homes;

- rural care, service provider managed health care in non-urban locations;

- residential care, managed health care in certified facilities.

Thematic analysis results are shown in Table 1 and each category is discussed below.

Table 1. Summary of study findings.

\begin{tabular}{|l|l|l|l|}
\hline Category & Settings & Technologies & Interventions \\
\hline $\begin{array}{l}\text { Remote } \\
\text { Consultations }\end{array}$ & $\begin{array}{l}\text { Self care; } \\
\text { Home care; } \\
\text { Rural care; } \\
\text { Residential care }\end{array}$ & $\begin{array}{l}\text { Video; } \\
\text { Telephone; } \\
\text { Multiparty } \\
\text { videoconferencing }\end{array}$ & $\begin{array}{l}\text { Aged Care and Geriatric assessments/reviews; } \\
\text { Specialist consultations; Indigenous patients; } \\
\text { Primary care; Rehabilitation; Hospital outreach; } \\
\text { Emergency care; Allied Health; Dentistry; } \\
\text { Nutrition; Daily checkup }\end{array}$ \\
\hline $\begin{array}{l}\text { Remote } \\
\text { Monitoring }\end{array}$ & $\begin{array}{l}\text { Self care; } \\
\text { Home care; } \\
\text { Residential care; }\end{array}$ & $\begin{array}{l}\text { Monitoring devices; } \\
\text { Monitoring systems; } \\
\text { Vital signs surveillance; } \\
\text { Mobile phone/apps }\end{array}$ & $\begin{array}{l}\text { Home living assistance; Primary care; COVID- } \\
19 \text { screening; COVID-19 monitoring; Smart } \\
\text { home system }\end{array}$ \\
\hline $\begin{array}{l}\text { Independent } \\
\text { Living Support }\end{array}$ & $\begin{array}{l}\text { Home care; } \\
\text { Residential care }\end{array}$ & $\begin{array}{l}\text { Pendant/alert button; } \\
\text { Personal wearables; } \\
\text { Mobile phone/apps; } \\
\text { Intelligent accessories }\end{array}$ & $\begin{array}{l}\text { Alarm/distress response services; Respiratory } \\
\text { services; Daily living activities; Hearing aid } \\
\text { configuration }\end{array}$ \\
\hline $\begin{array}{l}\text { Person-Carer } \\
\text { Communications }\end{array}$ & $\begin{array}{l}\text { Self care; } \\
\text { Home care; } \\
\text { Residential care }\end{array}$ & $\begin{array}{l}\text { Telephone; } \\
\text { Tablet/iPad; } \\
\text { Mobile phone/apps; } \\
\text { Internet voice devices }\end{array}$ & $\begin{array}{l}\text { Home care services delivery; Independent living } \\
\text { support services delivery; Care services } \\
\text { management; Entertainment and social services; } \\
\text { Video captioning }\end{array}$ \\
\hline
\end{tabular}

\subsection{Remote Consultations}

To date the major digital technology-based intervention in aged care has been the application of communications technologies to support health consultations funded by the Medical Benefits Scheme (MBS). Consultations with specialists supported by General Practitioners (GPs) have been the main focus, although in a few cases GPs have been able to undertake primary healthcare activities with residents in residential care. Use of these technologies occurred in less than $1 \%$ of consultations prior to the COVID19 epidemic. At the peak of the epidemic in Australia during April 2020, about 40\% of consultations were provided using the recently new items in the MBS enable health professionals to arrange telephone of video consultations direct to people at home [7]. Examination of subsequent MBS data showed that people over 60 years received 240,000 consultations in 2020, compared with 500,000 face to face consultations for all age groups [8]. Only 9,000 consultations to this older age group used video conferencing. Using information from a number of general practices in south-eastern Australia following the introduction of MBS telehealth items, the highest usage rates of telephone or video conferencing were for Mental Health, Alcohol and Other Drug, Dementia or Alzheimer's Disease [8].

\subsection{Remote Monitoring}

The second major digital technology-based intervention, largely un-funded by government, is remote monitoring of health conditions which enables older people with chronic diseases and other conditions to live independently in their home remain out of hospital. While application of remote monitoring has already been adopted by some age care providers on the basis of evidence for the above benefits [9], it is not yet a 
mainstream component of aged care. Unlike remote consultations, no government funding initiatives directly related to COVID-19 were provided to address remote monitoring costs. Consequently the majority of the examples identified in this study consisted of wider deployment of existing systems solutions or external third party services, to support healthcare in the homes of older people through the use of medical vital signs monitoring and associated communications. A few new services have appeared which are specifically aimed at COVID-19 vital signs monitoring for those in isolation or at high risk, offered as outreach initiatives by major health services $[10,11]$.

\subsection{Independent Living Support}

Another area for digital technologies being actively used in the aged care sector for the COVID-19 pandemic to support persons living independently, in home or community settings, and ageing in place under the supervision of informal or formal carers. Options may include access to $24 / 7$ on-call services, coordination of self care and home care, cooperation in management of health conditions, reducing social isolation, and better access for people unable to travel. Many technologies can be employed for these purposes, and sometimes multiple technologies have been packaged into one integrated program. For instance, the 'Staying Healthy Living Well' program is designed to support the health and wellbeing, and chronic disease management of seniors over the age of 70 years of age, via group education sessions using online coaching with a Telehealth Nurse and vital signs monitoring in collaboration with GPs, based around patient care plans [12]. In other cases technologies serve a single purpose, such as provision of alarm services possibly including audio or video interaction. While these types of systems have been in the market for some time, reliance on them during the COVID-19 pandemic has increased due to the higher proportion of older people maintaining self-isolation, or being subject to quarantine controls in aged care settings.

\subsection{Person-Carer Communication}

While many companies offer digital technology-based human intercommunications and social interaction solutions as consumer services, including embedded functions such as social media or entertainment streaming, there are relatively few products for dedicated care team interaction. One reason for this is the need to achieve interoperability between potentially several different software systems already adopted for independent use by each of the cooperating parties. Another reason is that the business model involves a number of parties cooperating in a shared ecosystem which requires controls over sensitive aspects such as billing, scheduling and information privacy. This requires adoption of underlying standardised information exchange and control protocols, with associated impacts on complexity and expense [13]. Some adaptations of existing platform solutions for COVID-19 situations have been deployed cooperatively by technology companies and aged care organisations e.g. $[14,15]$.

\section{Adoption Issues}

In this study, two major issues influencing the use of digital technology in the aged care sector were identified: firstly, the need to build workforce capability and user confidence in the use of new practices such as telehealth, and secondly availability and access to 
physical facilities, information technology and communications resources. A common theme for these issues was a need to develop strategies, policies, standards and regulations to mutually support more effective access to healthcare for older people.

The Royal Australian College of General Practitioners (RACGP) recently identified some telehealth related workforce issues in residential care such as an insufficient number of Residential Aged Care Facility (RACF) staff available, variable training and use of standard clinical communication tools, heavy reliance on agency nursing staff and high staff turnover, staff where English is their second language [16], p. 9. These issues intersect with recommendations for technology oriented workforce reform made by the Aged Care Industry Information Technology Council, including sector-wide national strategy, technology as core in aged care workforce structure, provide opportunities for online learning and videoconferencing and enhance digital literacy, and extend inclusion to informal carers [6], p. 49. Rural practices have responded faster in the use of the new MBS telehealth items, perhaps because they have previously been users of telehealth services [17] which may indicate the importance of confidence and experience in the use of telehealth services. Improving client digital literacy is also a significant need.

The RACGP sees significant lack of appropriate infrastructure in RACFs is a barrier for GPs attending elderly people, including lack of suitable consultation spaces, suitable equipment and lighting, unified medical records [16], p. 6. Other barriers identified are exchange of health information between aged residential facilities and primary care services, connectivity issues within aged care facilities such as bandwidth and signal strength, and access to devices by clients.

\section{Conclusion}

The findings described above show that technology support for health care and independent living interventions has been deployed successfully across a number of service organisations using products from a number of technology vendors. With the advent of the COVID19 epidemic, this type of remote interactive healthcare support was necessary and signs are that the adaptation and use of technology for remote health consultations and remote health monitoring in particular has increased.

A key conclusion that can be drawn from the findings is that diverse combinations of digital technologies can be developed rapidly and effectively to support the many needs of older people to stay healthy and live independent. Remote consultations, remote monitoring, independent living support, and care communications were all achieved using a variety of solutions. While there are system complexities to be addressed in any new digital technology deployment, the technical aspects are seldom the major barrier to its realisation.

This study also suggests that while significant benefits could arise from increased application of digital technologies in health and aged care, there has been insufficient attention paid to addressing or strengthening the enabling factors. The extent of the achievable benefits will depend very much on building confidence in the use of telehealth technologies through collaborations, developing clinical frameworks, skills and digital literacies, providing appropriate physical, information and communications infrastructure and supportive funding models for services that use digital technologies to assist maintenance of the health and well-being of older people. 


\section{References}

[1] National Health and Hospitals Reform Commission, A Healthier Future For All Australians - Final Report, June 2009.

[2] Australian Medical Association, Inquiry into the quality of care in Residential Aged Care Facilities in Australia - AMA submission, February 2018.

[3] Australian Institute of Health and Welfare, Aged care, 2019. https://www.aihw.gov.au/reports/australiaswelfare/aged-care.

[4] Australian Institute of Health and Welfare, Services and places in aged care, 2019. https://genagedcaredata.gov.au/Topics/Services-and-places-in-aged-care.

[5] Royal Commission into Aged Care Quality and Safety, Review of innovative models of aged care Research Paper 3, January 2020.

[6] K. Barnett, A Technology Roadmap for the Australian Aged Care Sector, 2017. http://aciitc.com.au/wpcontent/uploads/2017/06/ACIITC_TechnologyRoadmap_2017.pdf.

[7] C.L. Snoswell, L.J. Caffery, G. Hobson, M.L. Taylor, H.M. Haydon, E. Thomas, A.C. Smith, Medicare Benefits Schedule (MBS) activity in Australia, April 2020. https://coh.centre.uq.edu.au/telehealth-andcoronavirus-medicare-benefits-schedule-mbs-activity-australia.

[8] Outcome Health, COVID-19 and Australian General Practice: A preliminary analysis of changes due to telehealth use, 2020. https://polargp.org.au/wp-content/uploads/2020/05/COVID19-Insights-Paper-3Telehealth.pdf.

[9] Feros Care, My health clinic at home pilot, 2014. https://www.feroscare.com.au/docs/defaultsource/default-document-library/mhcah-pilot-full-report-jan15.pdf.

[10] N. Croxon, Bendigo Health first hospital in Australia to use new telehealth platform for COVID-19 patients, Bendigo Advertiser, 24 April 2020.

[11] K. McDonald, Royal Melbourne harnesses REDCap for home monitoring during COVID-19, Pulse + IT, 4 June 2020.

[12] Healthily, Building the health literacy of older Australians, 2019. https://healthily.com.au/building-thehealth-literacy-of-older-australians/.

[13] A. Lyons, Applications for health, RACGP Good Practice 7:10, 2017.

[14] S. Cheu, New initiatives keep residents connected during COVID, Australian Ageing Agenda, 16 April 2020. https://www.australianageingagenda.com.au/facility-operations/new-initiatives-keep-residentsconnected-during-covid/.

[15] Catholic Care, Keeping people together through COVID-19, Catholic Outlook, 17 April 2020. https://www.catholicoutlook.org/wise-counsel-keeping-people-together-through-covid-19/.

[16] Royal Australian College of General Practitioners, Submission to the Royal Commission into Aged Care Quality and Safety - Statement of Dr Harry Nespolon, 2019.

[17] Outcome Health, COVID-19 and General Practice, Insights Paper no.2 - A predictive impact model for the healthcare sector, 2020. https://polargp.org.au/wp-content/uploads/2020/05/COVID19-Paper-2Impact-Model-on-Healthcare.pdf. 